\title{
Efficacy of indacaterol on quality of life and pulmonary function in patients with COPD and inhaler device preferences
}

This article was published in the following Dove Press journal:

International Journal of COPD

21 January 2014

Number of times this article has been viewed

\author{
Takeshi Ohno' \\ Shota Wada' \\ Souichirou Hanada' \\ Hirochiyo Sawaguchi' \\ Masato Muraki' \\ Yuji Tohda ${ }^{2}$
}

'Department of Respiratory Medicine and Allergology, Nara Hospital, Kinki University Faculty of Medicine, Ikoma, Japan; ${ }^{2}$ Department of Respiratory

Medicine and Allergology, Kinki

University School of Medicine,

Osakasayama, Japan
Correspondence: Masato Muraki

Department of Respiratory Medicine and Allergology, Nara Hospital, Kinki University Faculty of Medicine, I248-I Otoda-cho, Ikoma, Nara 630-0298, Japan

$\mathrm{Tel}+8 \mathrm{I} 743770880$

Fax +81743770890

Email muraki@nara.med.kindai.ac.jp
Background: Indacaterol is a novel, once-daily, inhaled, long-acting $\beta 2$-agonist for patients with chronic obstructive pulmonary disease (COPD). The study objective was to evaluate the efficacy of indacaterol on quality of life and pulmonary function in patients with COPD in a real-world setting, and also to evaluate its inhaler device $\left(\right.$ Breezhaler $\left.{ }^{\mathbb{R}}\right)$, which is important for both adherence and management.

Methods: Twenty-eight outpatients with COPD were treated with indacaterol (150 $\mu \mathrm{g}$ once daily for 8 weeks), and the effects on pulmonary function were evaluated using a questionnaire survey with the modified Medical Research Council (mMRC) dyspnea scale and COPD assessment test (CAT) before and after treatment. Similar investigations were also performed separately among different baseline medications. Moreover, original questionnaire surveys for indacaterol and its device were performed.

Results: Overall, mMRC dyspnea scale and CAT scores significantly improved $(1.96 \pm 1.04$ to $1.57 \pm 1.07$ and $17.39 \pm 8.23$ to $12.82 \pm 8.42$, respectively; $P<0.05$ ). Significant improvements in forced vital capacity (FVC) and forced expiratory volume in 1 second $\left(\mathrm{FEV}_{1}\right)$ were also observed on pulmonary function tests $(2.91 \pm 0.66 \mathrm{~L}$ to $3.07 \pm 0.65 \mathrm{~L}$ and $1.46 \pm 0.60 \mathrm{~L}$ to $1.58 \pm 0.59 \mathrm{~L}$, respectively; $P<0.05$ ). Replacement therapy from salmeterol to indacaterol significantly improved mMRC and FVC values, but did not significantly improve CAT scores or other pulmonary functions. Add-on therapy with indacaterol significantly improved mMRC score, CAT score, FVC, and $\mathrm{FEV}_{1}$, regardless of whether tiotropium was used as a baseline treatment. All subjects in a questionnaire survey found the inhaler device easy to use. There were no serious adverse events leading to treatment discontinuation.

Conclusion: Indacaterol is thought to be effective and well tolerated as a bronchodilator for the management of COPD. Treatment with indacaterol in addition to a long-acting muscarinic antagonist was also useful.

Keywords: indacaterol, COPD, quality of life, respiratory function, device

\section{Introduction}

Chronic obstructive pulmonary disease (COPD) is a leading cause of morbidity and mortality worldwide and results in an economic and social burden that is both substantial and increasing. ${ }^{1,2}$ It was reported that the overall lifetime risk of physician-diagnosed COPD at 80 years of age was $27.6 \%$ in a longitudinal cohort study. ${ }^{3}$ Improvements in quality of life $(\mathrm{QoL})$, such as exercise tolerance and physical activity, and the improvement of pulmonary function in addition to the prevention of exacerbation are expected in the medication management of patients with COPD. The principal therapies for COPD management are inhaled medications. However, various devices for inhalation exist. Satisfaction with the inhaler device is also 
positively correlated with improved adherence and clinical outcomes. ${ }^{4}$ Especially for elderly patients, it is thought that the merits of these devices reflect treatment successes. Indacaterol (Onbrez ${ }^{\circledR}$; Novartis Pharma, Tokyo, Japan) is a novel, inhaled, long-acting $\beta 2$-agonist (LABA) providing a fast onset of action ${ }^{5}$ and 24 hours of bronchodilation ${ }^{6-8}$ on once-daily dosing. A dose of $150 \mu \mathrm{g}$ of powder contained in a capsule is inhaled using its inhaler device $\left(\right.$ Breezhaler $^{\circledR}$; Novartis Pharma).

In the present study, an evaluation of the efficacy of indacaterol on QoL (the modified Medical Research Council [mMRC] dyspnea scale and COPD assessment test [CAT] scores) and pulmonary function was performed for patients with COPD in an open study in a real-world setting. Additionally, similar analyses were investigated in a salmeterol-to-indacaterol replacement group and in an indacaterol add-on group based on the presence or absence of the long-acting muscarinic antagonist (LAMA) tiotropium. Finally, a questionnaire survey was conducted for the inhaler device, which is important for both adherence and management.

\section{Materials and methods Subjects}

Twenty-eight outpatients with COPD who had been commuting to the Department of Respiratory Medicine and Allergology at Nara Hospital, Kinki University Faculty of Medicine, Ikoma, Japan, were enrolled. COPD was defined according to the Global initiative for chronic Obstructive Lung Disease (GOLD) 2011 criteria. ${ }^{9}$ Subjects were over 40 years old, had $>10$ pack-years of smoking status, and had stable disease with no exacerbations during the 3 months prior to the study. Twenty-six patients $(92.9 \%)$ were men and the mean age was $75.7 \pm 7.0$ years. Maximum inspiratory flow using an In-Check Oral Inspiratory Flow Meter ${ }^{\circledR}$ (Matsuyoshi and Co, Ltd, Tokyo, Japan) was $78.2 \pm 20.7 \mathrm{~L} / \mathrm{min}$ (using an adaptor for Diskus; A/A/D). The mean Brinkman Index was 1,175 (58.75 pack-years). Regarding the severity of airflow limitation, ${ }^{9}$ six patients were classified as mild (GOLD1), twelve were moderate (GOLD2), six were severe (GOLD3), and four were very severe (GOLD4). Two patients were undergoing long-term oxygen therapy and two had bronchial asthma complications. As baseline medications, 19 patients were receiving tiotropium, ten were receiving salmeterol, two were receiving theophylline, seven were receiving an inhaled glucocorticosteroid, and seven were receiving mucolytics (Table 1). All patients were ex-smokers and were not on active smoking cessation pharmacotherapy.
Table I Clinical characteristics of the subjects $(n=28)$

\begin{tabular}{ll}
\hline Age (years) & $75.7 \pm 7.0$ \\
Sex, male:female & $26: 2$ \\
Brinkman Index & $1,190 \pm 562$ \\
Severity of airflow limitation & \\
$\quad$ Mild & 6 \\
$\quad$ Moderate & 12 \\
Severe & 6 \\
Very severe & 4 \\
Peak inspiratory flow; L/min (range) & \\
With adaptor: A/A/D & $78.2 \pm 20.7$ (I27-44) \\
Without adaptor & $182.0 \pm 58.9$ (3I5-88) \\
Baseline medications & 19 \\
$\quad$ LAMA (tiotropium) & 10 \\
LABA (salmeterol) & 2 \\
Theophylline & 7 \\
ICS & 7 \\
Mucolytics & 2 \\
Long-term oxygen therapy & 2 \\
Asthma complications &
\end{tabular}

Abbreviations: ICS, inhaled glucocorticosteroid; LABA, long-acting $\beta 2$-agonist; LAMA, long-acting muscarinic antagonist.

\section{Protocol (study design)}

This study was performed in a real-world setting and was an open-label clinical trial with no randomization, no placebo group, and no blinding. All subjects visited the hospital in the morning and answered the mMRC and CAT questionnaires. A pulmonary function test using a CHESTAC-33 (CHEST MI, Tokyo, Japan) was performed 2-4 hours after the patients took their baseline medications. After receiving inhaler instructions from a pharmacist at the hospital, subjects started to inhale indacaterol $(150 \mu \mathrm{g})$ once daily, starting the next morning. Eight weeks ( \pm 1 week) later, they visited the hospital at a similar time in the morning. Then, they answered the mMRC, CAT, and original questionnaires for indacaterol (Onbrez) and the Breezhaler device (it was confirmed that no subjects experienced problems with Breezhaler usage during the visit). Spirometry was also performed 2-4 hours after indacaterol inhalation and after the administration of other morning medications. In addition, adverse events were investigated during the 8 week ( \pm 1 week) follow-up visit.

All ten patients taking salmeterol as a baseline controlling medication were switched to indacaterol. Other baseline medications, except for salmeterol, were continued.

Second, similar subanalyses were performed on the basis of different baseline medications: the groups treated with and without an LAMA (tiotropium) and the groups treated with and without an LABA (salmeterol).

The study protocol was approved by the Institutional Review Board at Nara Hospital, Kinki University Faculty 
of Medicine, and informed consent was obtained from all subjects.

\section{Statistical analysis}

Data are summarized as the mean \pm standard deviation. Statistical differences before and after treatment with indacaterol were assessed using paired $t$-tests. Statistical analyses were performed using $\mathrm{JMP}^{\circledR}$ version 10.0.2 statistical software (SAS Institute Japan, Tokyo, Japan), and a difference of $P<0.05$ was considered statistically significant.

\section{Results}

As one subject among the 28 patients could not perform the pulmonary function test after treatment, resulting from a mistake, their pulmonary function data were excluded from the analyses. In the questionnaire survey, some blank responses were also excluded from the analyses. All patients continued treatment with indacaterol during the study period, had no exacerbations, and did not require the use of a rescue inhaler.

Pre- and post-treatment mMRC dyspnea scale scores were significantly improved by treatment with indacaterol (1.96 \pm 1.04 to $1.57 \pm 1.07 ; P=0.0013$ ) (Figure 1A). CAT scores also significantly improved from $17.39 \pm 8.23$ to $12.82 \pm 8.42$ $(P=0.0003)$ after treatment with indacaterol (Figure 1B). Scores for each item on the CAT questionnaire are shown in Figure 2. Scores for questions one to seven of the total of eight questions were significantly improved $(P<0.05)$. In pulmonary function tests, treatment with indacaterol significantly

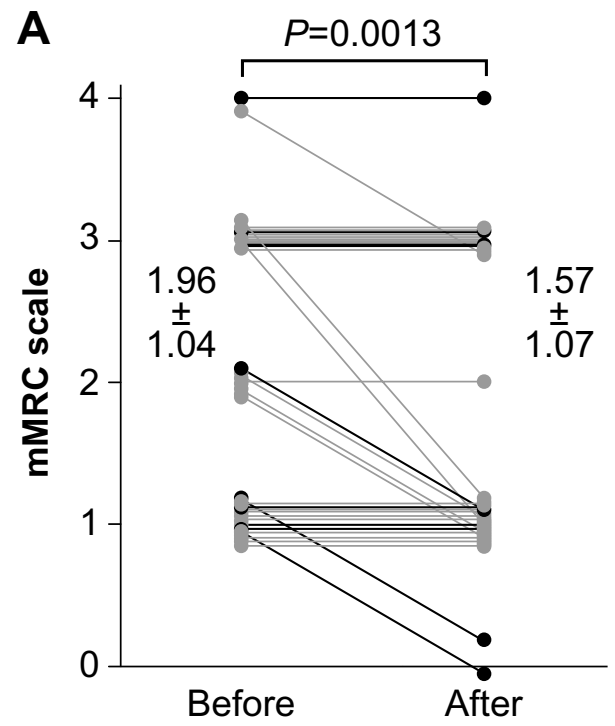

improved forced vital capacity (FVC), forced expiratory volume in 1 second $\left(\mathrm{FEV}_{1}\right)$, and flow at $25 \%$ forced vital capacity $\left(\mathrm{V}_{25}\right)(P<0.05$ for each) (Figure 3$)$.

Subanalyses performed based on treatment with or without an LAMA (tiotropium) as a baseline medication are shown in Table 2. In patients treated with tiotropium, mMRC scale, CAT score, FVC, and $\mathrm{V}_{25}$ significantly improved $(2.33 \pm 1.12$ to $1.67 \pm 1.12,13.78 \pm 4.99$ to $10.22 \pm 4.87,1.45 \pm 0.65 \mathrm{~L}$ to $1.64 \pm 0.56 \mathrm{~L}$, and $0.17 \pm 0.10 \mathrm{~L}$ to $0.26 \pm 0.10 \mathrm{~L} ; P<0.05$ for each). In patients treated with tiotropium, mMRC scale score, CAT score, FVC, and $\mathrm{FEV}_{1}$ significantly improved (1.79 \pm 0.98 to $1.53 \pm 1.07,19.11 \pm 8.99$ to $14.05 \pm 9.53$, $2.92 \pm 0.68 \mathrm{~L}$ to $3.08 \pm 0.66 \mathrm{~L}$, and $1.47 \pm 0.60 \mathrm{~L}$ to $1.56 \pm 0.61 \mathrm{~L}$; $P<0.05$ for each).

Subanalyses based on groups who had not been treated with salmeterol, those who received indacaterol add-on therapy (the add-on group), and those who had been treated with salmeterol and switched to indacaterol (replacement group) are shown in Table 3 . In the add-on group, mMRC scale score, CAT score, $\mathrm{FEV}_{1}$, and $\mathrm{V}_{25}$ significantly improved (1.94 \pm 1.00 to $1.50 \pm 0.86,17.28 \pm 6.44$ to $12.17 \pm 6.60$, $1.63 \pm 0.59 \mathrm{~L}$ to $1.75 \pm 0.55 \mathrm{~L}$, and $0.20 \pm 0.09 \mathrm{~L}$ to $0.22 \pm 0.08 \mathrm{~L}$; $P<0.05$ for each). In the replacement group, $\mathrm{mMRC}$ and FVC significantly improved $(2.00 \pm 1.15$ to $1.70 \pm 1.42$ and $2.66 \pm 0.52 \mathrm{~L}$ to $2.84 \pm 0.61 \mathrm{~L} ; P<0.05$ for each).

Original questionnaire surveys for indacaterol and the Breezhaler device were conducted, and responses were obtained from 26 subjects. A total of $61.5 \%$ of the total responded "I want to continue Onbrez", and all subjects

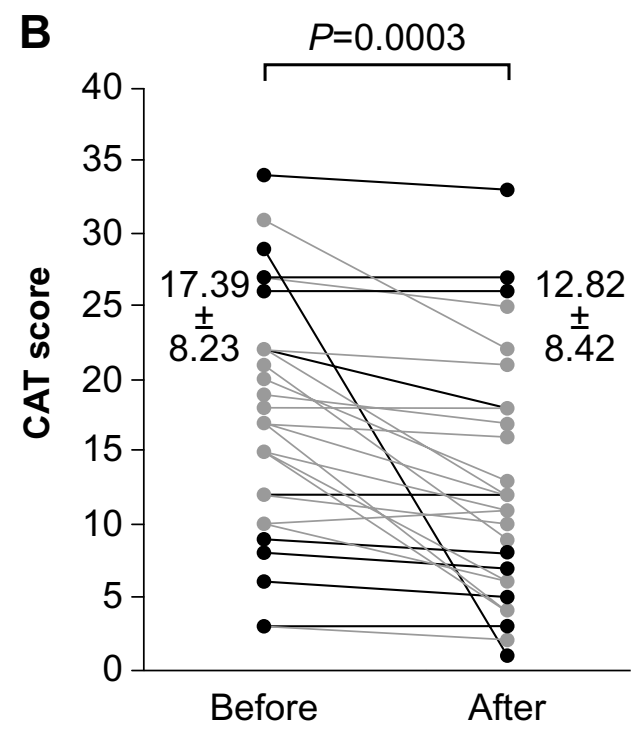

Figure I Comparison of mMRC dyspnea scale and CAT scores pre- and post-treatment with indacaterol. The mMRC dyspnea scale (A) and the CAT score (B) significantly improved after treatment with indacaterol $(P=0.0013$ and $P=0.0003$, respectively).

Notes: Add-on group with indacaterol $(n=18)$ for gray lines. Replacement group with indacaterol $(n=10)$ for black lines.

Abbreviations: CAT, chronic obstructive pulmonary disease assessment test; mMRC, modified Medical Research Council. 


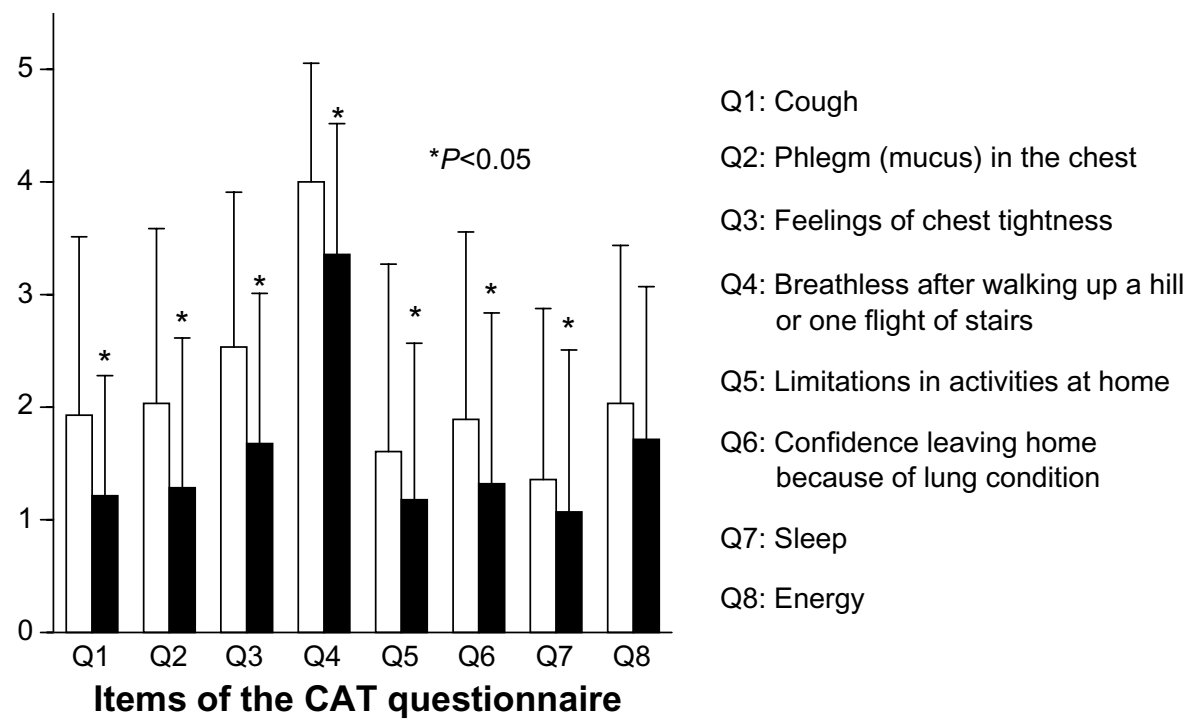

Figure 2 Comparison of scores for each item of the CAT questionnaire pre- and post-treatment with indacaterol. Scores for questions one to seven of the total of eight questions were significantly improved by treatment with indacaterol ( $* P<0.05$ for each). Abbreviation: CAT, chronic obstructive pulmonary disease assessment test.
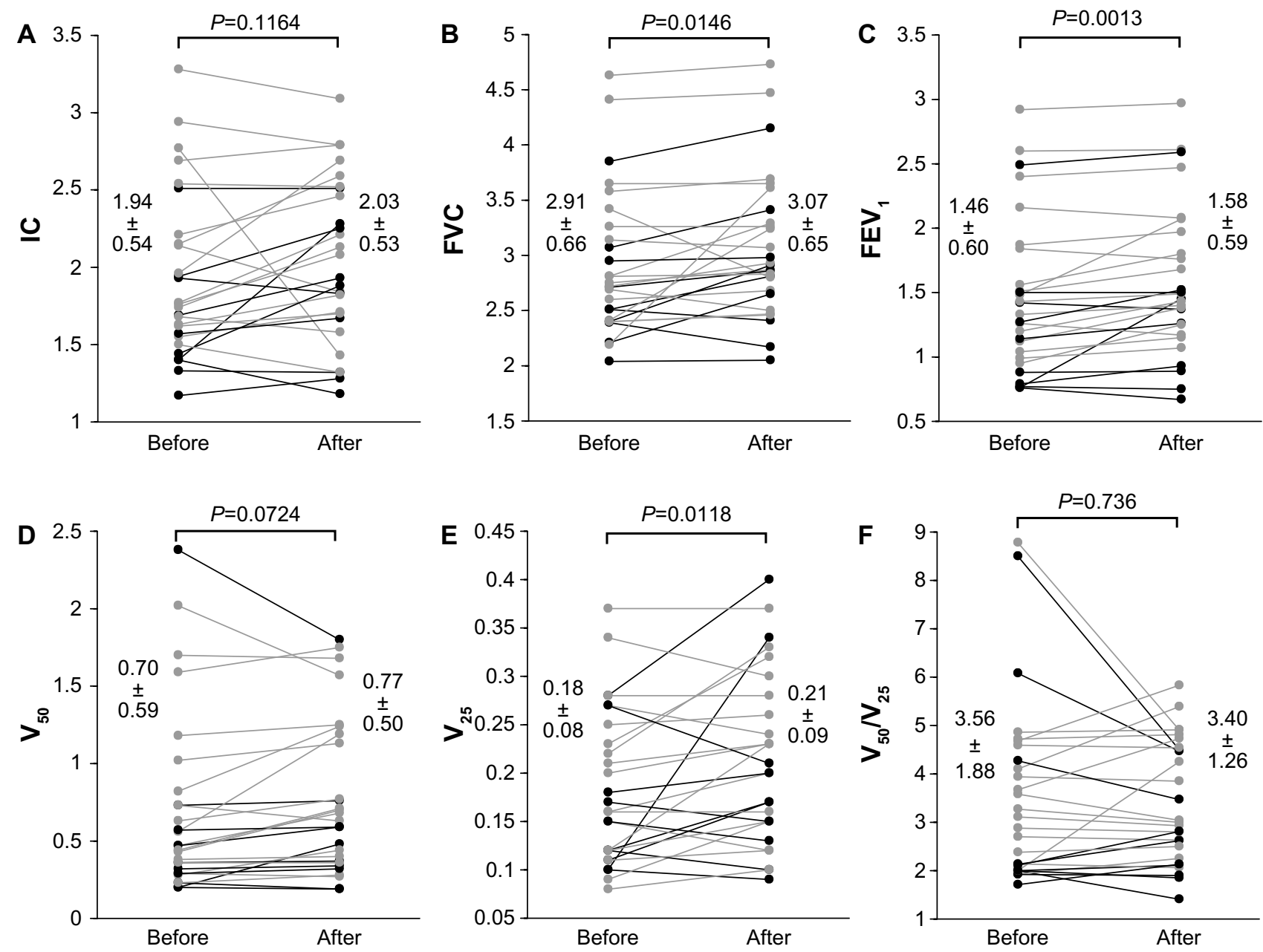

Figure 3 Pulmonary function tests pre- and post-treatment with indacaterol. The IC (A), FVC (B), FEV $(\mathbf{C}), \mathrm{V}_{50}(\mathbf{D}), \mathrm{V}_{25}(\mathbf{E})$, and $\mathrm{V}_{50} / \mathrm{V}_{25}(\mathbf{F})$ pulmonary functions were compared pre- and post-treatment with indacaterol. FVC, FEV , and $V_{25}$ were significantly improved by treatment with indacaterol ( $P<0.05$ for each).

Notes: Add-on group with indacaterol $(n=17)$ for gray lines. Replacement group with indacaterol $(n=10)$ for black lines.

Abbreviations: IC, inspiratory capacity; $\mathrm{FEV}_{1}$, forced expiratory volume in I second; FVC, forced vital capacity; $\mathrm{V}_{25}$, flow at $25 \%$ forced vital capacity; $\mathrm{V}_{50}$, flow at $50 \%$ forced vital capacity. 
Table 2 Subanalyses based on treatment with or without LAMA

\begin{tabular}{|c|c|c|c|c|c|c|}
\hline & \multicolumn{3}{|c|}{$\begin{array}{l}\text { Add-on group with indacaterol in patients treated } \\
\text { without LAMA }\end{array}$} & \multicolumn{3}{|c|}{$\begin{array}{l}\text { Add-on group with indacaterol in patients treated } \\
\text { with LAMA }\end{array}$} \\
\hline & Pretreatment & Post-treatment & $P$-value & Pretreatment & Post-treatment & $P$-value \\
\hline QoL & $(n=9)$ & & & $(n=19)$ & & \\
\hline $\mathrm{mMRC}$ & $2.33 \pm 1.12$ & $1.67 \pm 1.12$ & 0.025 & $1.79 \pm 0.98$ & $1.53 \pm 1.07$ & 0.010 \\
\hline CAT (total) & $13.78 \pm 4.99$ & $10.22 \pm 4.87$ & 0.018 & $19.11 \pm 8.99$ & $14.05 \pm 9.53$ & 0.003 \\
\hline QI & $0.89 \pm 0.93$ & $0.78 \pm 0.83$ & 0.173 & $2.42 \pm 1.61$ & $1.42 \pm 1.12$ & 0.009 \\
\hline Q2 & $0.89 \pm 0.93$ & $0.56 \pm 0.73$ & 0.040 & $2.58 \pm 1.50$ & $1.63 \pm 1.42$ & 0.003 \\
\hline Q3 & $2.78 \pm 1.20$ & $1.78 \pm 0.97$ & 0.020 & $2.42 \pm 1.46$ & $1.63 \pm 1.50$ & 0.002 \\
\hline Q4 & $3.89 \pm 1.17$ & $3.22 \pm 1.30$ & 0.011 & $4.05 \pm 1.03$ & $3.42 \pm 1.12$ & 0.005 \\
\hline Q5 & $1.1 \mathrm{I} \pm \mathrm{I} .27$ & $0.78 \pm 0.67$ & 0.173 & $1.84 \pm 1.80$ & $1.37 \pm 1.61$ & 0.060 \\
\hline Q6 & $1.78 \pm 1.56$ & $0.89 \pm 0.78$ & 0.034 & $1.95 \pm 1.75$ & $1.53 \pm 1.74$ & 0.021 \\
\hline Q7 & $1.22 \pm 1.64$ & $0.89 \pm 1.54$ & 0.173 & $1.42 \pm 1.50$ & $1.16 \pm 1.42$ & 0.048 \\
\hline Q8 & $1.22 \pm 0.83$ & $1.33 \pm 0.87$ & 0.827 & $2.42 \pm 1.46$ & $1.89 \pm 1.52$ & 0.038 \\
\hline Pulmonary function & $(n=8)$ & & & $(n=19)$ & & \\
\hline IC & $1.90 \pm 0.5 \mathrm{I}$ & $2.1 I \pm 0.54$ & 0.094 & $1.95 \pm 0.57$ & $2.00 \pm 0.53$ & 0.304 \\
\hline FVC & $2.87 \pm 0.64$ & $3.05 \pm 0.69$ & 0.208 & $2.92 \pm 0.68$ & $3.08 \pm 0.66$ & 0.007 \\
\hline FEV & $1.45 \pm 0.65$ & $1.64 \pm 0.56$ & 0.034 & $1.47 \pm 0.60$ & $1.56 \pm 0.61$ & 0.010 \\
\hline$V_{50}$ & $0.8 I \pm 0.77$ & $0.87 \pm 0.57$ & 0.262 & $0.65 \pm 0.5 \mathrm{I}$ & $0.72 \pm 0.48$ & 0.096 \\
\hline $\mathrm{V}_{25}$ & $0.17 \pm 0.10$ & $0.26 \pm 0.10$ & 0.014 & $0.19 \pm 0.07$ & $0.20 \pm 0.08$ & 0.204 \\
\hline$V_{50} / V_{25}$ & $4.17 \pm 2.20$ & $3.4 I \pm I .44$ & 0.098 & $3.30 \pm 1.73$ & $3.39 \pm 1.21$ & 0.366 \\
\hline
\end{tabular}

Abbreviations: CAT, chronic obstructive pulmonary disease assessment test; FEV , forced expiratory volume in I second; FVC, forced vital capacity; IC, inspiratory capacity; LAMA, long-acting muscarinic antagonist; mMRC, modified Medical Research Council; QoL, quality of life; $\mathrm{V}_{25}$, flow at $25 \%$ forced vital capacity; $\mathrm{VC}_{50}$, flow at $50 \%$ forced vital capacity.

responded "Yes" for device ease of handling and ease of use. Furthermore, 24 subjects $(92.3 \%)$ responded that they felt like they could inhale (Table 4).

Responses for reasons the patients felt they could inhale were obtained from 21 of those 24 subjects. Reasons included (multiple answers were allowed) $71.4 \%$ responding "By the sweet taste when I inhale", 52.4\% responding "I can confirm the inhalation because the inhalation capsule is transparent", and $47.6 \%$ responding "By hearing the sound when I inhale" (Table 4).

Table 3 Subanalyses in the indacaterol add-on and salmeterol-to-indacaterol replacement

\begin{tabular}{|c|c|c|c|c|c|c|}
\hline & \multicolumn{3}{|c|}{$\begin{array}{l}\text { Add-on group with indacaterol in patients treated } \\
\text { without LABA }\end{array}$} & \multicolumn{3}{|c|}{$\begin{array}{l}\text { Add-on group with indacaterol in patients treated } \\
\text { with LABA }\end{array}$} \\
\hline & Pretreatment & Post-treatment & $P$-value & Pretreatment & Post-treatment & $P$-value \\
\hline QoL & $(n=18)$ & & & $(n=10)$ & & \\
\hline $\mathrm{mMRC}$ & $1.94 \pm 1.00$ & $1.50 \pm 0.86$ & 0.008 & $2.00 \pm 1.15$ & $1.70 \pm 1.42$ & 0.041 \\
\hline CAT (total) & $17.28 \pm 6.44$ & $12.17 \pm 6.60$ & 0.0003 & $17.60 \pm 11.17$ & $|4.00 \pm| \mid .30$ & 0.111 \\
\hline QI & $2.06 \pm 1.55$ & $1.22 \pm 0.88$ & 0.009 & $1.70 \pm 1.70$ & $1.20 \pm 1.40$ & 0.182 \\
\hline Q2 & $2.28 \pm 1.32$ & $1.33 \pm 1.08$ & 0.0007 & $1.60 \pm 1.90$ & $1.20 \pm 1.75$ & 0.172 \\
\hline Q3 & $2.44 \pm 1.29$ & $1.50 \pm 1.20$ & 0.0005 & $2.70 \pm 1.57$ & $2.00 \pm 1.56$ & 0.055 \\
\hline Q4 & $3.94 \pm 1.06$ & $3.28 \pm 1.07$ & $<0.000$ I & $4.10 \pm 1.10$ & $3.50 \pm 1.35$ & 0.084 \\
\hline Q5 & $1.61 \pm 1.50$ & $1.17 \pm 1.10$ & 0.0596 & $1.60 \pm 2.01$ & $1.20 \pm 1.87$ & 0.172 \\
\hline Q6 & $\mathrm{I} .78 \pm \mathrm{I} .40$ & $1.11 \pm 1.02$ & 0.007 & $2.10 \pm 2.13$ & $1.70 \pm 2.16$ & 0.111 \\
\hline Q7 & $1.28 \pm 1.13$ & $0.89 \pm 1.08$ & 0.045 & $1.50 \pm 2.12$ & $1.40 \pm 1.96$ & 0.172 \\
\hline Q8 & $1.89 \pm 1.18$ & $1.67 \pm 1.03$ & 0.166 & $2.30 \pm 1.77$ & $1.80 \pm 1.87$ & 0.122 \\
\hline Pulmonary function & $(n=17)$ & & & $(n=10)$ & & \\
\hline IC & $2.11 \pm 0.55$ & $2.16 \pm 0.53$ & 0.333 & $1.64 \pm 0.40$ & $\mathrm{I} .8 \mathrm{I} \pm 0.45$ & 0.057 \\
\hline FVC & $3.05 \pm 0.70$ & $3.21 \pm 0.66$ & 0.078 & $2.66 \pm 0.52$ & $2.84 \pm 0.61$ & 0.023 \\
\hline $\mathrm{FEV}_{1}$ & $1.63 \pm 0.59$ & $1.75 \pm 0.55$ & 0.004 & I. $18 \pm 0.54$ & $1.29 \pm 0.56$ & $0.07 I$ \\
\hline$V_{50}$ & $0.77 \pm 0.55$ & $0.89 \pm 0.49$ & 0.030 & $0.58 \pm 0.66$ & $0.56 \pm 0.47$ & 0.567 \\
\hline $\mathrm{V}_{25}$ & $0.20 \pm 0.09$ & $0.22 \pm 0.08$ & 0.018 & $0.16 \pm 0.07$ & $0.20 \pm 0.10$ & 0.115 \\
\hline $\mathrm{V}_{50} / \mathrm{V}_{25}$ & $3.73 \pm 1.63$ & $3.79 \pm 1.20$ & 0.584 & $3.27 \pm 2.31$ & $2.73 \pm 1.09$ & 0.124 \\
\hline
\end{tabular}

Abbreviations: CAT, chronic obstructive pulmonary disease assessment test; $\mathrm{FEV}_{1}$, forced expiratory volume in I second; FVC, forced vital capacity; IC, inspiratory capacity; LABA, long-acting $\beta 2$-agonist; mMRC, modified Medical Research Council; QoL, quality of life; $\mathrm{V}_{25}$, flow at $25 \%$ forced vital capacity; $\mathrm{VC}_{50}$, flow at $50 \%$ forced vital capacity. 
Table 4 Questionnaire survey for indacaterol $\left(O n b r e z^{\circledR}\right)$ and the Breezhaler ${ }^{\circledR}$ device

\begin{tabular}{ll}
\hline & $\mathbf{n}(\%)$ \\
\hline About continuation of Onbrez & \\
I definitely want to continue & $2(7.7)$ \\
I want to continue & $14(53.8)$ \\
Equivocal & $10(38.5)$ \\
I want to stop & $0(0)$ \\
I definitely want to stop & $0(0)$ \\
Is handling the Breezhaler easy? & \\
Yes & $26(100)$ \\
No & $0(0)$ \\
Is it easy to use the Breezhaler? & \\
Yes & $26(100)$ \\
No & $0(0)$ \\
Did you feel that you could inhale? & \\
Yes & $24(92.3)$ \\
No & $2(7.7)$ \\
How could you feel it? (response: $n=2$ I) & \\
I can confirm the inhalation because & \\
$\quad$ The inhalation capsule is transparent & II (52.4) \\
By hearing the sound when I inhale & $10(47.6)$ \\
By a sweet taste when I inhale & I5 (7I.4)
\end{tabular}

Notes: Onbrez ${ }^{\circledR}$ (Novartis Pharma, Tokyo, Japan), Breezhaler ${ }^{\circledast}$ (Novartis Pharma, Tokyo, Japan).

The most frequent adverse event observed was coughing immediately after inhalation, in six patients. In addition, three reports of hoarseness and two reports of dry mouth were observed in four subjects. The two patients who complained of dry mouth were both treated with tiotropium as a baseline medication. However, these symptoms were mild and did not lead to discontinuation of indacaterol treatment. All patients continued treatment with indacaterol after the present study (Table 5).

\section{Discussion}

Once, it was considered that anticholinergics (muscarinic antagonists) demonstrated a greater bronchodilation effect than 32 -agonists in patients with COPD. ${ }^{9,10}$ In fact, of the long-acting bronchodilators, tiotropium showed a higher efficacy than salmeterol. ${ }^{11}$ However, indacaterol, a new LABA, was shown to be at least as effective as tiotropium and with a faster onset of action. ${ }^{12}$ Indacaterol has shown a powerful bronchodilation effect with a mechanism different

Table 5 Adverse events

\begin{tabular}{ll}
\hline Adverse events & $\mathbf{n}$ \\
\hline Immediate coughing after inhalation (disappearance & 6 \\
within I minute) & \\
Hoarseness & 3 \\
Dry mouth & 2 \\
Mouth discomfort & I \\
\hline
\end{tabular}

from that of the LAMAs, and its efficacy has been shown. Pharmacologic therapy in COPD is used to reduce symptoms, reduce the frequency and severity of exacerbations, and improve health status and exercise tolerance. ${ }^{13}$ There are several validated questionnaires to assess symptoms in patients with COPD. GOLD recommends the use of the mMRC questionnaire or the CAT. The well-known mMRC questionnaire assesses only disability resulting from breathlessness; however, the CAT covers a broader range of the impact of COPD on the patient's daily life and wellbeing. ${ }^{13}$ In the present study, these two questionnaires were used for the assessment of the patients' QoL, and the efficacy of bronchodilation was assessed by spirometry. Because inhaler adherence is very important in the management of COPD, ${ }^{14}$ questionnaire surveys for indacaterol (Onbrez) and its inhaler device (Breezhaler) were performed.

It has been reported that patients receiving indacaterol had clinically significant improvements in symptoms of dyspnea compared with placebo. ${ }^{15}$ Among the 23 eligible patients, 14 were receiving tiotropium $18 \mu \mathrm{g} /$ day (by a Handihaler ${ }^{\mathbb{R}}$ ), and nine were receiving no therapy. Treatment with indacaterol improved both pulmonary function and QoL. ${ }^{16}$ Add-on therapy with indacaterol also improved expiratory reserve volume and exercise capacity, although a significant difference was not noted in the improvement of $\mathrm{FEV}_{1} \cdot{ }^{17}$ Overall, indacaterol therapy improved the QoL of patients with COPD in the present study. In addition, $\mathrm{FVC}, \mathrm{FEV}_{1}$, and $\mathrm{V}_{25}$ were improved in pulmonary function tests. Significantly more patients receiving indacaterol reported less need for a rescue inhaler (short-acting $\beta 2$-agonist) than LABA recipients. ${ }^{18,19}$ In the present study, no patients used a short-acting $\beta 2$-agonist in a rescue capacity. Indacaterol might be a useful option, even for the treatment of acute exacerbations of COPD. ${ }^{20}$

Indacaterol was at least as effective as tiotropium in improving clinical outcomes..$^{21,22}$ However, a comparison of indacaterol and tiotropium under blinded conditions confirmed a statistically significant improved effect of indacaterol over tiotropium for dyspnea (transition dyspnea index) and health status (the St George's Respiratory Questionnaire). ${ }^{23}$ Furthermore, compared with tiotropium monotherapy, indacaterol plus tiotropium provided greater bronchodilation and lung deflation (reflected by an increased resting inspiratory capacity). ${ }^{24}$ Regardless of the use or nonuse of tiotropium, add-on therapy with indacaterol significantly improved mMRC scale score, CAT score, and $\mathrm{FEV}_{1}$ in the present study. These results support COPD guideline recommendations to combine bronchodilators with different mechanisms of action. 
Using trough $\mathrm{FEV}_{1}$ as a measure of therapeutic effect, indacaterol was superior to other $\beta 2$-agonists, tiotropium, and placebo at weeks 12,26 , and 52 . Indacaterol had a greater effect on the transition dyspnea index than salmeterol. ${ }^{25}$ Although this study did not consider the trough value, the switch from salmeterol did not significantly improve pulmonary function, except for FVC. However, mMRC score was significantly improved, even in the present small sample size. Therefore, it is thought that indacaterol treatment contributed to improvements of QoL more than salmeterol.

Adherence is crucial for optimizing clinical outcomes in COPD, with nonadherence resulting in significant health and economic burdens. ${ }^{26}$ Adherence in patients with COPD is affected by multiple factors associated with the patient, their clinician, and society. ${ }^{27}$ Patient-related factors include health beliefs and self-efficacy. Treatment-related factors include each treatment requiring a different technique for administration, in addition to the need for multiple inhalers, and are especially burdensome for older COPD patients. In the present study, indacaterol and its device seemed to be regarded favorably by patients with COPD. These results may contribute to better clinical outcomes through satisfactory adherence.

The most frequently observed adverse event was coughing immediately after inhalation; hoarseness and dry mouth were also observed. However, these adverse events were mild and did not result in the discontinuation of indacaterol treatment. Indacaterol demonstrated excellent tolerability.

A limitation of the present study is the small sample size. There were no analyses of the patients' adherence as distinguished from inhaler device preference; therefore, future investigations regarding inhaler adherence are needed. However, despite the small sample size and regardless of the quality of adherence, pulmonary functions and QoL were improved. In addition, there are no analyses comparing inhaler devices in the present study with other inhaler devices, and further studies are needed to better clarify patient preferences.

\section{Conclusion}

In summary, indacaterol is both safe and effective in the management of COPD. Furthermore, add-on therapy with an LAMA is also effective in improving clinical outcomes. The inhaler device is easy to use and was well regarded by the patients, which can contribute to medication adherence.

\section{Disclosure}

The authors report no conflicts of interest in this work.

\section{References}

1. Lopez AD, Shibuya K, Rao C, et al. Chronic obstructive pulmonary disease: current burden and future projections. Eur Respir J. 2006;27: 397-412.

2. Mathers CD, Loncar D. Projections of global mortality and burden of disease from 2002 to 2030. PLoS Med. 2006;3:e442.

3. Gershon AS, Warner L, Cascagnette P, Victor JC, To T. Lifetime risk of developing chronic obstructive pulmonary disease: a longitudinal population study. Lancet. 2011;378:991-996.

4. Mäkelä MJ, Backer V, Hedegaard M, Larsson K. Adherence to inhaled therapies, health outcomes and costs in patients with asthma and COPD. Respir Med. 2013;107:1481-1490.

5. Balint B, Watz H, Amos C, Owen R, Higgins M, Kramer B; INSURE Study Investigators. Onset of action of indacaterol in patients with COPD: comparison with salbutamol and salmeterol-fluticasone. Int J Chron Obstruct Pulmon Dis. 2010;5:311-318.

6. Dahl R, Chung KF, Buhl R, et al. Efficacy of a new once-daily longacting inhaled beta2-agonist indacaterol versus twice-daily formoterol in COPD. Thorax. 2010;65:473-479.

7. Bleecker ER, Siler T, Owen R, Kramer B. Bronchodilator efficacy and safety of indacaterol $150 \mu \mathrm{g}$ once daily in patients with COPD: an analysis of pooled data. Int J Chron Obstruct Pulmon Dis. 2011;6: 431-438.

8. Kornmann O, Dahl R, Centanni S, et al. Once-daily indacaterol versus twice-daily salmeterol for COPD: a placebo-controlled comparison. Eur Respir J. 2011;37:273-279.

9. Gross NJ, Skorodin MS. Role of the parasympathetic system in airway obstruction due to emphysema. N Engl J Med. 1984;311:421-425.

10. Schocken DD, Roth GS. Reduced beta-adrenergic receptor concentrations in ageing man. Nature. 1977;267:856-858.

11. Vogelmeier C, Hederer B, Glaab T, et al. Tiotropium versus salmeterol for the prevention of exacerbations of COPD. NEngl J Med. 2011;364: 1093-1103.

12. Vogelmeier C, Ramos-Barbon D, Jack D, et al. Indacaterol provides 24-hour bronchodilation in COPD: a placebo-controlled blinded comparison with tiotropium. Respir Res. 2010;11:135.

13. Global Initiative for Chronic Obstructive Lung Disease (GOLD). Global strategy for diagnosis, management, and prevention of chronic obstructive lung disease [updated 2013]. Available from: http://www. goldcopd.org/uploads/users/files/GOLD_Report_2013_Feb20.pdf. Accessed December 9, 2013.

14. Vestbo J, Anderson JA, Calverley PM, et al. Adherence to inhaled therapy, mortality and hospital admission in COPD. Thorax. 2009;64: 939-943.

15. Han J, Dai L, Zhong N. Indacaterol on dyspnea in chronic obstructive pulmonary disease: a systematic review and metaanalysis of randomized placebo-controlled trials. BMC Pulm Med. 2013;13:26

16. Hataji O, Naito M, Ito K, Watanabe F, Gabazza EC, Taguchi O. Indacaterol improves daily physical activity in patients with chronic obstructive pulmonary disease. Int J Chron Obstruct Pulmon Dis. 2013;8:1-5.

17. Mroz RM, Minarowski L, Chyczewska E. Indacaterol add-on therapy improves lung function, exercise capacity and life quality of COPD patients. Adv Exp Med Biol. 2013;756:23-28.

18. Korn S, Kerwin E, Atis S, Amos C, Owen R, Lassen C; INSIST study group. Indacaterol once-daily provides superior efficacy to salmeterol twice-daily in COPD: a 12-week study. Respir Med. 2011;105: 719-726.

19. Feldman GJ. Improving the quality of life in patients with chronic obstructive pulmonary disease: focus on indacaterol. Int J Chron Obstruct Pulmon Dis. 2013;8:89-96. 
20. Segreti A, Fiori E, Calzetta L, et al. The effect of indacaterol during an acute exacerbation of COPD. Pulm Pharmacol Ther. 2013;26(6): $630-634$.

21. Donohue JF, Fogarty C, Lötvall J, et al. Once-daily bronchodilators for chronic obstructive pulmonary disease: indacaterol versus tiotropium. Am J Respir Crit Care Med. 2010;182:155-162.

22. Mahler DA, Buhl R, Lawrence D, McBryan D. Efficacy and safety of indacaterol and tiotropium in COPD patients according to dyspnoea severity. Pulm Pharmacol Ther. 2013;26:348-355.

23. Buhl R, Dunn LJ, Disdier C, et al. Blinded 12-week comparison of once-daily indacaterol and tiotropium in COPD. Eur Respir J. 2011;38: $797-803$.
24. Mahler DA, D’Urzo A, Bateman ED, et al. Concurrent use of indacaterol plus tiotropium in patients with COPD provides superior bronchodilation compared with tiotropium alone: a randomised, doubleblind comparison. Thorax. 2012;67:781-788.

25. Jiang FM, Liang ZA, Zheng QL, Wang RC, Luo J, Li CT. Safety and efficacy of 12-week or longer indacaterol treatment in moderate-to-severe COPD patients: a systematic review. Lung. 2013;191:135-146.

26. Lareau SC, Yawn BP. Improving adherence with inhaler therapy in COPD. Int J Chron Obstruct Pulmon Dis. 2010;5:401-406.

27. Restrepo RD, Alvarez MT, Wittnebel LD, et al. Medication adherence issues in patients treated for COPD. Int J Chron Obstruct Pulmon Dis. 2008;3:371-384.

\section{Publish your work in this journal}

The International Journal of COPD is an international, peer-reviewed journal of therapeutics and pharmacology focusing on concise rapid reporting of clinical studies and reviews in COPD. Special focus is given to the pathophysiological processes underlying the disease, intervention programs, patient focused education, and self management protocols.

\section{Dovepress}

This journal is indexed on PubMed Central, MedLine and CAS. The manuscript management system is completely online and includes a very quick and fair peer-review system, which is all easy to use. Visit http://www.dovepress.com/testimonials.php to read real quotes from published authors. 